\title{
A percepção do especialista sobre o tema mobilidade urbana
}

\author{
Renata Cardoso Magagnin ${ }^{1} ;$ Antônio Nélson Rodrigues da Silva ${ }^{2}$
}

\begin{abstract}
Resumo: O conceito de mobilidade urbana ainda é muito recente no Brasil e os problemas a ele relacionados ainda não estão muito claros para uma parcela significativa da população. Este artigo tem como objetivo identificar se isto também se verifica com técnicos e planejadores trabalhando especificamente nos campos do planejamento urbano e de transportes. O estudo foi realizado em uma cidade média brasileira, com uma ferramenta computacional concebida para ajudar na definição de um Sistema de Indicadores de Mobilidade Urbana. Neste estudo de caso foram utilizadas técnicas de avaliação qualitativa que permitiram confrontar a percepção dos usuários acerca do conceito de mobilidade urbana antes e depois do uso da ferramenta. A abordagem permitiu demonstrar que de fato havia inicialmente uma visão parcial da mobilidade por parte dos técnicos. Também conduziu à conclusão de que parece ter havido uma significativa ampliação no seu grau de conhecimento sobre o tema ao longo do processo.
\end{abstract}

\begin{abstract}
The concept of urban mobility is still recent in Brazil. As a consequence, the problems related to the concept are not clear for a significant part of the population. The objective of this study is to examine if this is also the case for technicians and planners working specifically in the fields of urban and transportation planning. The study was carried out in a Brazilian medium-sized city, through an application with a computational tool originally designed to help in the construction of a System of Urban Mobility Indicators. Qualitative analyses tools were applied for comparing the participants' perception about the urban mobility concept before and after the used of the tool. The approach was able to reveal that the professionals had indeed a partial view of mobility at the beginning of the research. It also led to the conclusion that their knowledge about the theme evolved significantly during the process.
\end{abstract}

\section{INTRODUÇÃO}

Historicamente, questões de planejamento urbano encontram-se associadas de forma intrínseca a aspectos de transporte, isto é, o crescimento das cidades influencia e é influenciado pelos meios de transporte disponíveis à sua população. Mais ainda, a forma como se dá o processo de circulação urbana interfere diretamente na demanda por transportes, nas áreas destinadas a estacionamento, nos congestionamentos, etc. $\mathrm{O}$ crescimento urbano desordenado, provocado pelo espalhamento espacial, o aumento excessivo no uso do automóvel, a falta de infra-estrutura urbana, a poluição do meio ambiente, entre outras, são questões que interferem na qualidade de vida da população. Estes fatores têm contribuído para que pesquisadores, decisores e tomadores de decisão busquem novas formas de minimizar, discutir e encontrar soluções para estas questões urbanas.

O processo de planejamento tradicional, em que cada problema urbano deve ser resolvido separadamente, não pode mais ser utilizado para solucionar os atu-

\footnotetext{
${ }^{1}$ Renata Cardoso Magagnin, Departamento de Arquitetura, Urbanismo e Paisagismo, Universidade Estadual Paulista. Bauru, SP, Brasil (e-mail: magagnin@faac.unesp.br).

${ }^{2}$ Antônio Nélson Rodrigues da Silva, Departamento de Transportes, Escola de Engenharia de São Carlos, Universidade de São Paulo. São Carlos, SP, Brasil (e-mail: anelson@sc.usp.br).
}

Manuscrito recebido em 25/1/2008 e aprovado para publicação em $1 / 4 / 2008$. Este artigo é parte de TRANSPORTES, volume XVI, número 1 , de junho de 2008. ISSN: 1415-7713. ais problemas urbanos, uma vez que é hoje de conhecimento de pesquisadores e decisores que há fortes inter-relações entre os diversos problemas urbanos. Para contrapor-se a este sistema de planejamento que não atende mais às necessidades urbanas e da população, disseminou-se mundialmente um processo de planejamento mais integrado, onde as questões de uso do solo e transporte são entendidas de uma forma mais ampla, como em Loukopoulos e Scholz (2004). A antiga denominação do planejamento de transportes passa a incorporar um conjunto de novos conceitos, entre eles o da mobilidade urbana, e ainda o conceito de planejamento associado aos transportes é ampliado, incorporando as visões de infra-estrutura, circulação e transporte público associados a questões de uso do solo, meio ambiente, entre outros aspectos.

Outro conceito incorporado ao planejamento dos transportes (ou ao planejamento da mobilidade urbana) refere-se à sustentabilidade. Segundo Steg e Gifford (2005) o desenvolvimento sustentável no planejamento de transportes está associado ao equilíbrio entre os aspectos ambientais, econômicos e sociais, tanto no presente como nas futuras intervenções urbanas. Este conceito foi adotado inicialmente na Europa, América do Norte e Austrália (Richardson, 2005). No Brasil esta visão ainda é recente, e o conceito está sendo incorporado gradativamente nas discussões dos Planos Diretores de Transportes e Mobilidade (Silva et al., 2007). Cabe mencionar que a inexistência de uma política de transportes explícita e coerente no país e nos municípios pode dificultar, ou mesmo invi- 
abilizar, o estabelecimento de um planejamento de transportes que incorpore os conceitos de "mobilidade urbana" e da "sustentabilidade".

Alguns países da Europa, os Estados Unidos e o Canadá têm adotado indicadores como um modo de avaliar e monitorar a mobilidade em nível local (Gudmundsson, 2001, Gudmundsson 2004). Em cada um destes países foi utilizado um enfoque diferente para o emprego do conceito de mobilidade sustentável valendo-se de indicadores (ver Nicolas et al., (2003)). $\mathrm{Na}$ Europa, por exemplo, são adotadas medidas de integração das questões ambientais com as demais políticas públicas; nos Estados Unidos os indicadores estão sendo utilizados para a elaboração de planos estratégicos em todos os níveis e no Canadá são utilizados elementos e estruturas advindas das experiências européias e norte americanas (Gudmundsson, 2001; Gudmundsson, 2004; Silva et al., 2007).

No Brasil, a utilização de indicadores faz parte da política de Mobilidade Urbana elaborada pelo governo federal, onde a definição de um Sistema de Indicadores é parte integrante dos produtos a serem definidos na elaboração dos Planos Diretores de Transportes e Mobilidade Municipais. Este sistema de indicadores pode ser utilizado nas etapas de planejamento e monitoração do plano.

Embora a nova abordagem já tenha começado a ser discutida no Brasil, diversas questões relacionadas ao conceito de mobilidade urbana ainda não estão, no entanto, muito claros para uma parcela significativa da população. Mais grave do que isso pode ser a constatação de que esta afirmação também se aplica aos técnicos ligados às áreas de planejamento urbano e de transportes, razão pela qual esta pesquisa se propõe a verificar essa hipótese. Assim, após essa breve introdução, são apresentados no item 2 alguns dos elementos mais relevantes para a aplicação proposta. Isso inclui uma breve discussão do conceito de mobilidade urbana, a apresentação de uma ferramenta computacional desenvolvida como parte de um Sistema de Apoio a Decisão para o planejamento da mobilidade urbana, e aspectos básicos das técnicas de avaliação empregadas. No item 3 é discutida a metodologia, no item 4 são apresentados e analisados os resultados da aplicação realizada e, finalmente, no item 5, são apresentadas e discutidas as conclusões e considerações finais.

\section{FUNDAMENTAÇÃO TEÓRICA}

Para melhor compreensão da pesquisa aqui realizada, três aspectos merecem especial atenção: $i$ ) o novo conceito de mobilidade urbana sustentável e sua posição frente ao conceito tradicional usado em planejamento de transportes, ii) o sistema PLANUTS, ferra- menta computacional desenvolvida para auxiliar no planejamento da mobilidade urbana sustentável e usada na avaliação aqui conduzida, iii) uma breve discussão acerca de algumas das técnicas que podem ser utilizadas para avaliar o grau de percepção e sobretudo de mudança dessa percepção nos indivíduos, visando a sua utilização na aplicação proposta.

\subsection{Mobilidade urbana sustentável}

A mobilidade pode ser definida como um atributo relacionado aos deslocamentos realizados por indivíduos nas suas atividades de estudo, trabalho, lazer e outras. Nesse contexto, as cidades desempenham um papel importante nas diversas relações de troca de bens e serviços, cultura e conhecimento entre seus habitantes, mas isso só é possível se houver condições adequadas de mobilidade para as pessoas (Ministério das Cidades, 2006).

O desenvolvimento sustentável é aquele que responde às necessidades do presente sem comprometer a capacidade das gerações futuras de responder às suas próprias necessidades. É um processo que associa três importantes dimensões: ambiental, econômica e social, estabelecendo uma correlação entre esses três pólos, garantindo a eficácia econômica e a proteção do meio ambiente, sem perder de vista as finalidade sociais que são a luta contra a pobreza, as desigualdades, a exclusão e a busca da eqüidade. De forma análoga, segundo a UITP - International Association of Public Transport, a base para uma mobilidade sustentável está na inter-relação entre os seguintes componentes: meio ambiente, economia e sociedade. $\mathrm{O}$ equilíbrio entre estes três componentes proporcionará: a realização das necessidades das pessoas no que se refere à qualidade de vida e acessibilidade; o respeito ao habitat, causando o menor impacto pelas atividades humanas e, no tocante à economia, ela está relacionada aos recursos disponíveis, ou ao modo como estes recursos possam satisfazer as necessidades de cada cidadão (Black at al., 2002; Steng e Gifford, 2005; Richardson, 2005).

As cidades que consideram as políticas relacionadas à integração entre mobilidade e sustentabilidade urbana garantem maior eficiência e dinamismo das funções urbanas, com maior e melhor circulação de pessoas e mercadorias. Isto se reflete na valorização do espaço público, na sustentabilidade e no desenvolvimento da cidade, conciliando as dimensões ambiental, social e econômica (Ministério das Cidades e IBAM, 2004).

Um dos problemas enfrentados pela maioria das cidades brasileiras, já atingindo inclusive as de porte médio, refere-se à questão da mobilidade urbana. A dependência no uso do automóvel tem causado grande impacto no fluxo de tráfego. Associado a este proble- 
ma, as atuais políticas de crescimento e desenvolvimento urbano não têm privilegiado a utilização de meios de transportes mais sustentáveis (tais como, a bicicleta, o modo a pé e o transporte público). Como conseqüência do uso indiscriminado do automóvel nas áreas urbanas, tem-se: o aumento dos congestionamentos, da energia consumida no setor de transportes e do ruído e das emissões de gases tóxicos.

Outro problema visivelmente identificado nas áreas urbanas e que influencia diretamente no planejamento da mobilidade é a crescente dispersão espacial, observada em muitas cidades, inclusive brasileiras. A localização de novas residências e serviços nas áreas periféricas, localizadas distantes das áreas centrais, está afetando diretamente a mobilidade nestas cidades. As cidades não estão preparadas para oferecer serviços a esta nova demanda. Em alguns casos, é evidente a dissociação que existe entre o planejamento urbano e o de transportes, particularmente na questão do planejamento do uso do solo urbano. Estas questões têm contribuído para aumentar as disparidades na oferta de serviços aos diversos segmentos urbanos, com conseqüência direta sobre a mobilidade urbana (Litman, 2006).

\subsection{O sistema PLANUTS}

A sigla PLANUTS tem a origem nos termos PLANejamento Urbano e de Transportes integrado e Sustentável. Este Sistema de Suporte à Decisão foi desenvolvido, pelos autores deste artigo, como uma alternativa que pode ser adotada num processo de planejamento da mobilidade urbana participativa envolvendo múltiplos segmentos da comunidade. O objetivo do sistema é auxiliar no planejamento e monitoramento da mobilidade urbana, principalmente, em cidades brasileiras de pequeno e médio porte; ou seja, ele traz subsídios para planejadores e tomadores de decisão, nas áreas de planejamento urbano e de transportes, através de um sistema que contêm modelos e ferramentas que podem auxiliar em um processo de tomada de decisão integrado e participativo. Em síntese, tratase de uma ferramenta computacional destinada a promover um processo integrado e sustentável para elaboração e monitoramento de Planos Diretores de Mobilidade Urbana, cujos detalhes podem ser obtidos em Magagnin (2008).

A concepção do sistema PLANUTS está fundamentada na associação dos princípios e métodos do processo de participação popular tradicional com os recursos que a internet pode proporcionar aos usuários (decisores). O modelo de participação adotado é o individual, ou seja, as informações são armazenadas e disponibilizadas para análise de forma individualizada. O sistema permite a análise das avaliações de cada usuário após a finalização do processo de avaliação do módulo corrente. O processo de decisão ocorre através de um consenso geral das decisões parciais resultantes dos diferentes estágios de avaliação e da escolha de alternativas (cenários) definidas pelos diversos agentes participantes. $\mathrm{O}$ acesso ao sistema é realizado através da internet; ou seja, os participantes podem acessar o sistema em qualquer local e horário, desde que o módulo para avaliação esteja ativo. Entre os possíveis locais de acesso, além do trabalho e da residência, estão os terminais públicos. Seria o caso, por exemplo, do Poupatempo do estado de São Paulo, local que reúne vários órgãos e empresas prestadoras de serviço público para atender aos cidadãos em postos fixos de 11 municípios da capital e interior, além de postos móveis.

O sistema PLANUTS é formado pelos seguintes componentes: i) Interface na internet - é representada pela página do projeto na internet, composta por páginas $h t m l$ que contêm informações do projeto, do município e sobre mobilidade. ii) Módulo de Avaliação da Mobilidade Urbana - é composto por quatro módulos de avaliação interdependentes que possibilitam: o gerenciamento das informações, a exploração, e a avaliação da mobilidade urbana e um módulo de gerenciamento das avaliações. O Sistema foi construído adotando-se uma estrutura modular, ou seja, buscou-se estruturar as informações de acordo com o grau de conhecimento da população sobre a questão da mobilidade urbana e assim possibilitar a participação de múltiplos segmentos da sociedade no processo de avaliação e/ou monitoramento da Mobilidade Urbana. A definição de cada Módulo é apresentada no Quadro 1 .

Em resumo, o Sistema PLANUTS foi elaborado para possibilitar uma nova visão no processo de tomada de decisão (principalmente dos decisores nãoespecialistas) nas diversas etapas da elaboração do Plano Diretor de Transportes e Mobilidade através dos seguintes resultados: i) definição de um Sistema de Indicadores de Mobilidade para o planejamento e monitoração da Mobilidade Urbana no município; ii) auxílio aos tomadores de decisão na formulação, definição ou avaliação das situações (cenários) através da identificação dos problemas de mobilidade associados a cada indicador avaliado e iii) fornecimento de um suporte à tomada de decisão através da análise dos possíveis impactos da adoção de determinada alternativa.

\subsection{Técnicas de avaliação qualitativa}

Para avaliar o grau de percepção e sobretudo de mudança dessa percepção em indivíduos, a partir de respostas dadas a questões formuladas em diferentes momentos ou condições, são necessárias técnicas específicas. Dentre as técnicas pesquisadas na literatura 
Quadro 1: Principais funções dos quatro Módulos de Avaliação da Mobilidade Urbana MÓDULOS DE AVALIAÇÃO DA MOBILIDADE URBANA

- Módulo I - avaliar as Categorias e Temas através da definição do "grau de importância" destes critérios. O objetivo é definir os aspectos relacionados ao planejamento e monitoramento da Mobilidade Urbana mais relevantes para a elaboração de um Plano Diretor de Transportes e Mobilidade Urbana participativo através da avaliação das seguintes Categorias e Temas associados à Mobilidade Urbana: Meio Ambiente e Transportes, Gestão dos Transportes, Infra-estrutura dos Transportes, Planejamento dos Transportes, e Aspectos Socioeconômicos dos Transportes.

- Módulo II - avaliar os Indicadores através da escolha de dois indicadores por Tema. Estes indicadores são definidos como sendo os "mais importantes" para avaliar a Mobilidade na cidade. O resultado desta avaliação irá definir os indicadores que deverão compor um Sistema de Indicadores de Mobilidade Urbana.

- Módulo III - avaliar os Indicadores através dos seguintes itens: problemas e soluções associados aos indicadores avaliados, definição dos indicadores "mais importantes" e "mais urgentes", e espacialização dos problemas de mobilidade mais importantes na cidade; ou seja, este módulo tem como objetivo definir as prioridades de ação na cidade, no que se refere à Mobilidade Urbana, a partir dos indicadores mais votados pela população no Módulo anterior. São avaliados: i) a Identificação dos Problemas e Soluções relacionados à mobilidade urbana; ii) a Identificação das Definições de Ação; e iii) o Diagnóstico dos indicadores na cidade.

- Módulo IV - avaliação dos cenários comparativos.

- Módulo Administrativo - visualização dos resultados dos Módulos I a IV e construção dos Módulos III e IV

especializada destacam-se: a análise de conteúdo e a construção de mapas cognitivos.

\subsubsection{Análise de conteúdo}

A análise de conteúdo é um conjunto de técnicas de análise utilizadas principalmente nas Ciências Sociais. No entanto, outras áreas de conhecimento também estão se apropriando destas técnicas para decodificarem as mensagens obtidas em entrevistas e questionários. $\mathrm{Na}$ área de Planejamento dos Transportes, por exemplo, esta técnica foi utilizada por Sant'Anna (2007) para avaliar a percepção de usuários idosos com relação ao sistema viário. Segundo aquela autora, a utilização da técnica de análise de conteúdo possibilitou ampliar o enfoque interdisciplinar (fenômenos sociológicos, psicológicos, físicos e técnicos) dos estudos de segurança de trânsito, permitindo assim que pudessem ser compreendidas as causas dos acidentes de trânsito em relação à população idosa.

A análise de conteúdo é um "conjunto de técnicas de análise das comunicações visando obter, por procedimentos, sistemáticos e objectivos de descrição do conteúdo das mensagens, indicadores (quantitativos ou não) que permitam a inferência de conhecimentos às condições de produção/recepção (variáveis inferidas) destas mensagens" (Bardin, 1977). Segundo Henry e Moscovici apud Bardin (1977) "tudo o que é dito ou escrito é susceptivel de ser submetido a uma análise de conteúdo".

Dentre as técnicas que compõem a metodologia de análise de conteúdo para a análise de respostas para questões abertas destacam-se: Análise Temática, Análise Léxica e Análise de Associação. A Análise Temática permite descobrir os principais sentidos da comunicação (respostas a questões abertas, entrevistas, etc.), onde a presença ou freqüência de um determinado índice (termo - frase ou palavra) pode ter algum significado no processo de análise. A Análise Léxica é realizada através da identificação de pala- vras-chave. Segundo Bardin (1977), para realizar a análise de um texto deve-se levar em consideração todas as "palavras", pois elas podem representar elementos chave (palavras-chave ou palavras-tema) de análise cujo significado pode contribuir para uma determinada análise.

Na Análise de Associação, também denominada de co-ocorrências, procura-se extrair do texto as relações entre os elementos da mensagem, ou seja, a relação de associação entre dois ou mais elementos na mesma unidade de contexto. Esta teoria foi esboçada por Baldwin e defendida por Osgood. Osgood propõe o seguinte procedimento metodológico para a realização deste tipo de análise: $i$ ) escolher as unidades de registro - palavras-chave, temas; ii) escolher as unidades de contexto e o recorte do texto - numa mensagem descontínua a unidade de contexto pode corresponder: a uma carta, a um artigo, a uma entrevista, etc; iii) codificar - realçar os elementos de cada fragmento para a obtenção de uma matriz que possam mostrar as co-ocorrências ou as associações; iv) calcular as coocorrências e $v$ ) representar e interpretar os resultados - os resultados podem ser representados através de tabelas de contingência, quadros de redes e de núcleos (clusters analysis).

\subsubsection{Mapas cognitivos}

A metodologia desenvolvida por Eden (1989) apud Pidd (2003) tem como objetivo auxiliar grupos no entendimento de problemas complexos, como por exemplo, na questão da tomada de decisão envolvendo múltiplos participantes. Os Métodos SODA I e SODA II (SODA - Strategic Options Development and Analysis, cuja tradução é Desenvolvimento e Análise de Ações Estratégicas) têm como objetivo decodificar as informações individuais (método SODA I) ou em grupo (método SODA II) através da construção de Mapas de Causa, também conhecidos como Mapas Cognitivos (ver Figuras 1 e 2). Os dois sistemas são parte da 
abordagem denominada Making Journey (JOintly Understanding, Reflecting and Negotiating stratEgY) e têm sido utilizados por Eden e outros pesquisadores no planejamento estratégico.

- Método SODA I - Segundo Pidd (2003) este método é utilizado quando um grupo de indivíduos tem seus pontos de vistas, que precisam ser direcionados para a tomada de decisão conjunta. $\mathrm{O}$ início do processo é separar os entrevistados de forma que cada membro possa desenvolver seu próprio mapa cognitivo. O mapa deve mostrar como eles expressam seus pensamentos. Cada um destes mapas compõe um mapa estratégico que servirá de base para as discussões e negociações do grupo (ver Figura 1).

- Método SODA II e Journey Making - Segundo descrições de Eden \& Ackermann (1998) apud Pidd (2003), deve ser aplicado diretamente com o grupo de decisores. Neste caso pode ser utilizado o software Group Explorer. Este mapa é utilizado pelo facilitador (Coordenador do grupo de decisão) para auxiliar o grupo na concordância da tomada de decisão (ver Figura 2).

A construção de Mapas Cognitivos, segundo Eden (1989) apud Pidd (2003), é uma forma de capturar os pontos de vista das pessoas através do desenvolvimento de um modelo. A idéia é que o analista (pesquisa- dor) traduza as entrevistas (inquéritos) para um mapa esquemático que represente a síntese dos pensamentos individuais ou de um grupo. Os Mapas Cognitivos são métodos que pertencem à área da Psicologia Ambiental; esta por sua vez, é uma disciplina que "procura" entender o pensamento e o sentimento das pessoas através de suas experiências pessoais. O termo "Mapa Cognitivo" é utilizado por Eden para transmitir conceitos das idéias das pessoas através de representação bidimensional (esquemas gráficos), onde os conceitos (definidos por pessoas ou grupos) são ligados uns aos outros. O objetivo é capturar as idéias dos entrevistados, individualmente ou em grupos, utilizando "palavras" definidas pelos participantes. A intenção deste método é auxiliar os participantes a entender a situação (problema) e definir ações. Para a construção do mapa cognitivo, Eden recomenda dispor os conceitos a partir do ponto mais alto para o ponto mais baixo do mapa (top down); sendo que o conceito principal ficará no topo do mapa.

Os Mapas Cognitivos são compostos por conceitos e $\operatorname{arcos}$ (cujas extremidades são compostas por setas, cuja direção pode indicar um link positivo ou negativo). O conceito representa uma idéia definida por uma pessoa ou um grupo, sendo que elas possuem algum significado para as pessoas envolvidas; estas idéias são expressas através de palavras. $O$ conceito deve

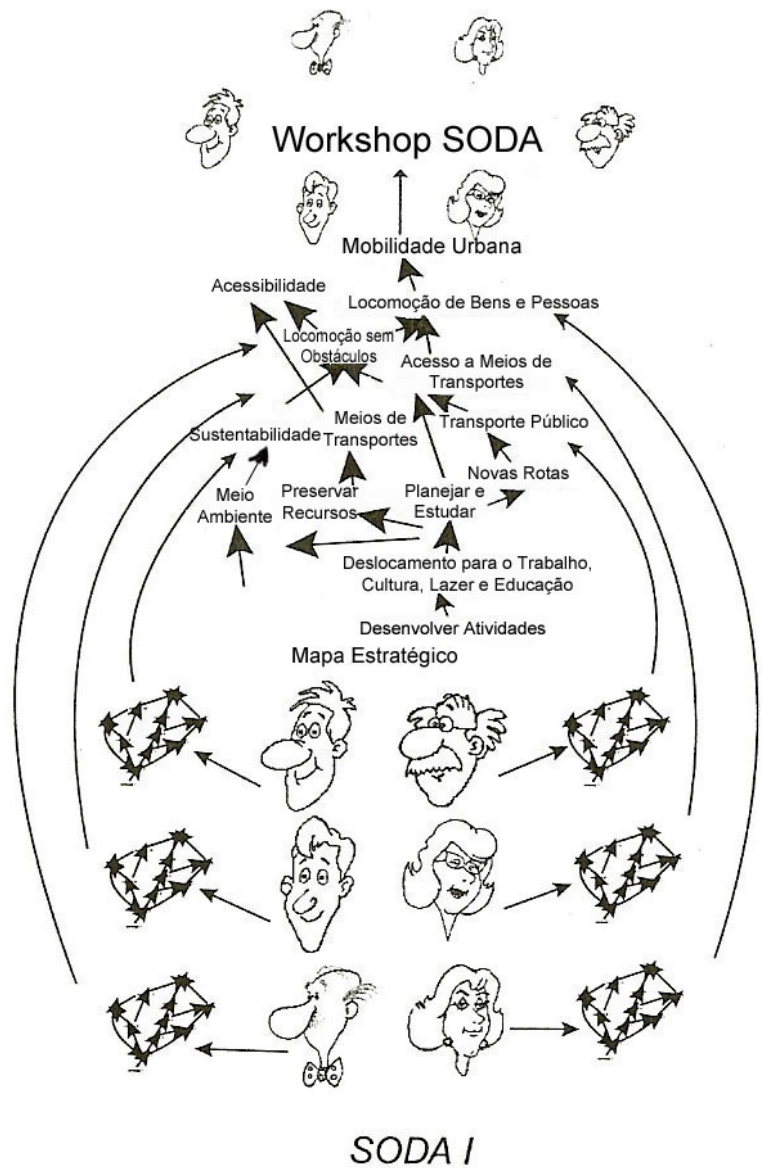

Figura 1: Mapas de Causa: SODA I Fonte: adaptado de Pidd (2003).

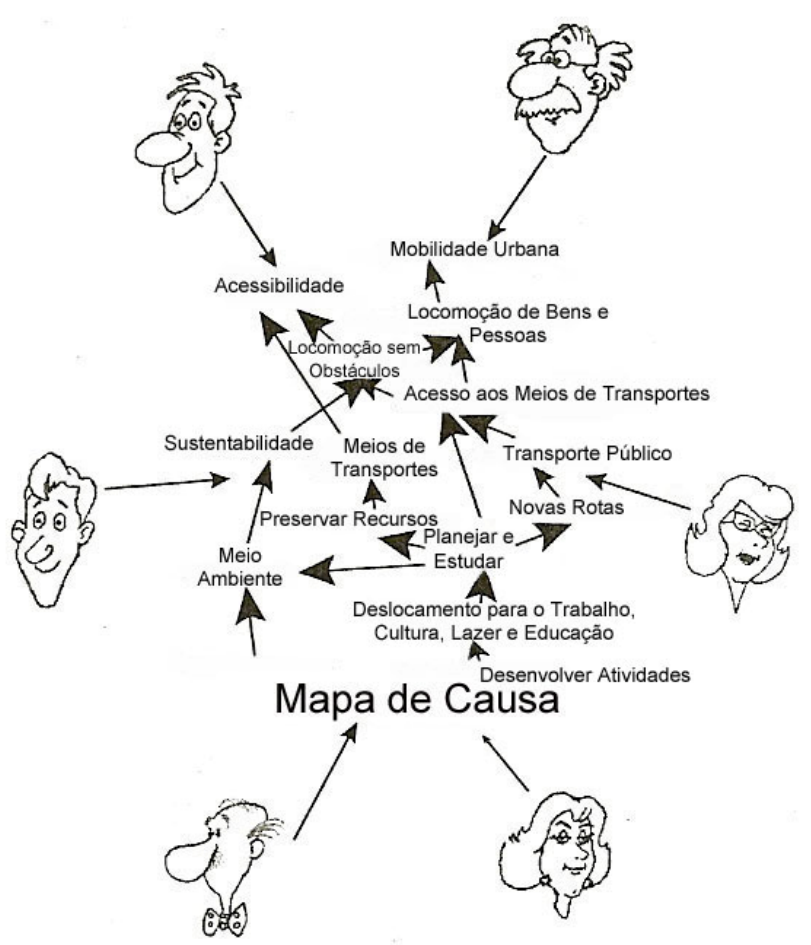

Journey Making (SODA II)

Figura 2: Mapas de Causa: SODA II Fonte: adaptado de Pidd (2003). 
capturar (expressar) a visão dos participantes. Em alguns casos o conceito pode ser definido através de dois pólos separados (denominados de conceitos bipolares); estes dois pólos podem esclarecer a definição do conceito inicial. Segundo Pidd (2003) conceitos similares podem apresentar significados (interpretações) diferentes, por esta razão, não é conveniente desprezá-los. No método SODA II não são definidos muitos conceitos bipolares. A direção dos arcos mostra a relação de direção dos conceitos (conceito inicial e final). Um arco mostra uma relação entre um par de conceitos. As setas devem ser posicionadas na direção do conceito inicial para o conceito final. As setas acompanhadas de um sinal negativo mostram uma causalidade negativa entre os dois conceitos. O sinal positivo ou negativo deve ser utilizado para expressar conceitos individuais e não o ponto de vista do consultor (pesquisador - interpretador).

Nesta pesquisa, para a análise dos questionários foi definida a utilização de uma combinação dos métodos desenvolvidos por Eden e Bardin, ou seja, foram utilizadas como referência as técnicas de construção de Mapas Cognitivos associadas às técnicas de Análise de Conteúdo (Análise Léxica e de Associação). As respostas dos questionários foram analisadas através da identificação de palavras-chave. Posteriormente foram construídos os Mapas Cognitivos a partir das inter-relações de cada palavra-chave para cada questionário avaliado. Na seqüência foram analisados, por comparação de palavras-chave, os Mapas Cognitivos para cada questão. Os detalhes do procedimento podem ser melhor compreendidos nos itens a seguir, onde é discutida a metodologia e são apresentados e analisados alguns dos resultados encontrados.

\section{METODOLOGIA}

Para a avaliação aqui proposta foi concebido um teste específico juntamente com a atividade denominada Capacitação técnica para a elaboração de plano diretor de mobilidade urbana - Definição de indicadores de mobilidade urbana, realizada de julho a setembro de 2007 na cidade de Bauru-SP. Essa atividade de capacitação tinha por objetivo apresentar aos participantes a ferramenta computacional PLANUTS, bem como o método desenvolvido para definir indicadores de mobilidade. Essa definição de indicadores visava a sua posterior inserção no Plano Diretor de Transportes e Mobilidade municipal que deverá ser executado em um futuro próximo (segundo o Artigo 253; $\S 1^{\circ}$ e $2^{\circ}$ da proposta de Lei do Plano Diretor Participativo do Município de Bauru, a cidade deverá elaborar o Plano Diretor de Transportes e Mobilidade em um prazo de um ano a partir de sua aprovação, de forma participativa).
$\mathrm{Na}$ condição de especialistas, participaram da atividade proposta técnicos ligados à área de Planejamento de Transportes e Planejamento Urbano da Prefeitura Municipal de Bauru, membros do Núcleo Gestor do Plano Diretor e delegados. Esses últimos são representantes da sociedade, que também participaram do desenvolvimento e aprovação do Plano Diretor Participativo do Município de Bauru. Os participantes foram selecionados de forma a atender às seguintes questões: i) representantes técnicos - foram escolhidos aqueles que poderão vir a conduzir a elaboração do Plano Diretor de Transportes e Mobilidade Participativo do município, e $i$ i) representantes da sociedade - sua escolha ocorreu em função do seu conhecimento do processo de discussão de um Plano Diretor. Para efeito das análises aqui conduzidas, somente os questionários dos sete técnicos que participaram da capacitação (item $i$ ) foram considerados.

No sistema PLANUTS a conceituação de mobilidade está contemplada na avaliação de um módulo (o de número I), através da definição das cinco Categorias e vinte Temas. Assim, os usuários podem associar à definição de Mobilidade elementos de Meio Ambiente, Gestão, Infra-estrutura, Planejamento e Aspectos Socioeconômicos. Com o intuito de verificar se o uso do Sistema PLANUTS poderia interferir no grau de percepção de cada usuário sobre as questões que envolvem a Mobilidade Urbana, foram desenvolvidos dois questionários: i) Questionário 1, para ser aplicado no início do primeiro dia da atividade de capacitação e ii) Questionário 2, para ser aplicado ao final do último dia de atividades. Os dois questionários continham perguntas abertas, fechadas e/ou de múltipla escolha.

A aplicação do Questionário 1 tinha por objetivo verificar o grau de conhecimento de cada participante a respeito dos temas Planejamento de Transportes e Mobilidade Urbana, e a definição e identificação de alguns problemas a eles associados no município. $\mathrm{O}$ Questionário 2 foi elaborado essencialmente para identificar as diferenças ou contribuições do sistema no conhecimento das questões relativas à mobilidade urbana. Em outras palavras, como o objetivo principal desta pesquisa era avaliar a hipótese inicial de que a visão de mobilidade urbana dos técnicos poderia ser também restrita, estes questionários deveriam, juntos, permitir identificar eventuais limitações dos conceitos apresentados inicialmente, bem como eventuais alterações cognitivas após a utilização da ferramenta computacional.

Para realizar a análise comparativa das respostas obtidas nos questionários aplicados antes e após a utilização do Sistema PLANUTS, adotou-se uma integração entre as seguintes metodologias de análise, discutidas no item 2 desse artigo: i) Análise de Conte- 
údo (de acordo com Bardin, 1977) e ii) Mapas Cognitivos (Mapas de Causa, de acordo com Eden, 1989). A análise de conteúdo foi utilizada para identificar nas respostas dos dois questionários, algumas palavraschave que pudessem servir de elementos de comparação, permitindo realizar a identificação na diferenciação do grau de conhecimento do grupo em relação à Mobilidade Urbana. Os Mapas Cognitivos (Mapas de Causa) foram utilizados como meio de representação dos elementos decodificados pela técnica de análise de conteúdo. Entretanto, ao invés da utilização de frases, como o método estabelece, foi utilizada a representação através de palavras-chave, uma vez que as respostas, na maioria das vezes, eram compostas de elementos muito sintéticos. Em alguns casos as respostas eram até mesmo compreendidas por uma série de palavras-chave.

\section{APRESENTAÇÃO E ANÁLISE DOS RESULTADOS}

Quanto às características gerais das respostas dos questionários, as perguntas abertas permitiram identificar o grau de conhecimento e a incorporação (no atual repertório de cada participante) dos diversos aspectos que estão associados intrinsecamente à questão da mobilidade urbana; enquanto que as respostas fechadas permitiram quantificar alguns dados e assim gerar um diagnóstico da mobilidade na cidade de Bauru.

Das 30 questões propostas para avaliação no Questionário 1,13 foram abertas e 17 fechadas e/ou de múltipla escolha. Para a análise das questões abertas utilizou-se o seguinte procedimento: primeiro realizou-se a transcrição das respostas de cada avaliador; posteriormente o conjunto de idéias extraídas das respostas foi organizado por afinidade (procurou-se idéias análogas que pudessem ser agrupadas) obtendo-se desta forma uma resposta mais consensual sobre cada tema em cada pergunta. Embora este questionário tenha sido elaborado para técnicos, as avaliações mostraram que os participantes possuem uma visão setorizada (fragmentada), ou seja, dominam os problemas que envolvem diretamente seu campo de atuação; não possuindo um conhecimento mais amplo de outras questões que envolvem o planejamento municipal. O Questionário 2, cujo objetivo era determinar o grau de percepção das questões relacionadas a mobilidade após a realização do curso de capacitação, possuía 20 questões, sendo 10 abertas e 10 de múltipla escolha e/ou fechadas. Essa diferença no número de questões não comprometeu a análise, uma vez que as questões que serviam ao interesse da presente avaliação constavam de ambos os questionários.

$\mathrm{Na}$ seqüência é apresentado o resultado de duas das análises realizadas, todas conduzidas através de Quadros (onde são identificadas e destacadas as palavraschave), e dos Mapas Cognitivos. Nos exemplos aqui apresentados, os Quadros 2 e 3 contêm as respostas dos especialistas, respectivamente, antes e depois da atividade proposta, para a questão que procurava uma definição para o conceito de mobilidade urbana, bem como os Mapas Cognitivos elaborados a partir dessas respostas, mostrados nas Figuras 3 e 4 (relacionadas ao Quadro 2) e Figuras 5 e 6 (relacionadas ao Quadro 3). Outras questões dos questionários foram comparadas e analisadas da mesma forma, mas a avaliação para esse artigo se concentra sobretudo nos resultados das análises daquelas questões que refletem mais diretamente a definição do conceito de mobilidade urbana.

A referência para a análise comparativa foi estabelecida a partir dos mapas construídos com base no Questionário 1 e sua comparação com o mapa construído a partir das respostas obtidas no Questionário 2. Foram identificados no segundo Mapa Cognitivo (denominado de Mapa 2, construído a partir do Questionário 2 e apresentado na Figura 4) os elementos (palavras-chave) que estavam presentes no Mapa Cognitivo denominado de Mapa 1 (Figura 3). Para auxiliar neste diagnóstico foram definidas cores diferenciadas para que as células pudessem representar elementos distintos no Mapa 2, isto é, foi adotado o fundo preto com letras brancas para as células que apresentaram "novas definições" e a cor cinza e borda mais grossa para aquelas definições que não estavam diretamente associadas ao termo Mobilidade Urbana. As células brancas com letras pretas indicavam elementos que haviam sido identificados tanto no primeiro como no segundo questionário, ou apenas no primeiro questionário. Não representavam, portanto, elementos de mudança.

Com relação à avaliação do Quadro 2, no Mapa Cognitivo 1 (Figura 3) a definição de Mobilidade Urbana foi dada pelos participantes através da associação dos seguintes elementos: infra-estrutura, deslocamento de pessoas e veículos, locação do mobiliário urbano e utilização de meios de transporte motorizado e nãomotorizado. No Mapa Cognitivo 2 (Figura 4) pode-se observar claramente uma ampliação desta definição através da inclusão dos seguintes itens: acessibilidade, mobilidade na área urbana e rural, circulação de bens (além das pessoas), planejamento, preservação e otimização de recursos.

No tocante ao Quadro 3, observando os dois Mapas Cognitivos pode-se afirmar que no Mapa 1 (Figura 5) os problemas de mobilidade identificados no primeiro questionário representavam problemas que estavam diretamente associados ao Planejamento de Transportes associado às questões de planejamento e de infraestrutura viária e também a questão do planejamento urbano associado ao planejamento de transportes. No 
Quadro 2: Transcrição das respostas dos especialistas para a questão que trata da definição de Mobilidade Urbana nos Questionários 1 e 2 .

\begin{tabular}{|c|c|c|}
\hline QUESTÃO & QUESTIONÁRIO 1 & QUESTIONÁRIO 2 \\
\hline $\begin{array}{l}\text { O que você entende por } \\
\text { Mobilidade Urbana? } \\
\text { (Questionários 1 e 2) } \\
\text { Objetivo - Identificar se } \\
\text { houve um avanço no grau } \\
\text { de conhecimento dos } \\
\text { participantes com relação } \\
\text { à questão da mobilidade } \\
\text { e do planejamento dos } \\
\text { transportes. }\end{array}$ & $\begin{array}{l}\text { - Aspectos relacionados ao deslocamento das } \\
\text { pessoas, veículos e da locação do mobiliário } \\
\text { urbano no contexto da cidade tendo influência } \\
\text { significativa no "ir e vir". } \\
\text { - É a característica que têm objetos e pessoas de } \\
\text { transitarem para determinado destino dentro } \\
\text { de certas regras no meio urbano. } \\
\text { - É a facilidade que o } \underline{\text { indivíduo tem em se }} \\
\text { locomover dentro de uma cidade, ou seja, se a } \\
\text { cidade lhe oferece condiçóes de locomoção } \\
\text { rápida e segura, tanto a pé quanto de transpor- } \\
\text { te motorizado, não esquecendo das pessoas } \\
\text { com necessidades especiais. } \\
\text { - É a possibilidade de deslocamento na cidade. } \\
\text { Tem relação com a infra-estrutura existente } \\
\text { (rede de vias, calçadas, transporte público), } \\
\text { mas também com a capacidade pessoal em } \\
\text { termos de possibilidade motora, física e de } \\
\text { recursos. } \\
\text { - A facilidade ou dificuldade com que as pesso- } \\
\text { as realizam os deslocamentos para efetuar su- } \\
\text { as atividades no espaço urbano. } \\
\text { - É a condição oferecida pela cidade do indiví- } \\
\text { duo chegar aos locais que pretende, tais como: } \\
\text { vias, sistema de transporte. } \\
\text { - É como as pessoas se locomovem dentro do } \\
\text { espaço urbano. }\end{array}$ & $\begin{array}{l}\text { - Mobilidade urbana é o meio pelo qual pode- } \\
\text { mos estudar e planejar o transporte e a loco- } \\
\text { moção de bens e pessoas visando a otimização } \\
\text { dos recursos e preservação dos mesmos. } \\
\text { - É a possibilidade de todas as pessoas se loco- } \\
\text { moverem dentro das cidades, sem obstáculos } \\
\text { as quais estas não possam transpor. Ainda, } \\
\text { acessarem os meios de transporte e as edifica- } \\
\text { ções, sem que encontrem obstáculos intrans- } \\
\text { poníveis. } \\
\text { - É a capacidade (ou possibilidade) das pessoas } \\
\text { e bens circularem pela cidade. Entendemos } \\
\text { que esse termo deva ser ampliado para con- } \\
\text { templar a zona rural, onde moram pessoas que } \\
\text { tem necessidades de educação, saúde, consu- } \\
\text { mo em geral, além das cargas (produção agrí- } \\
\text { cola, pecuária, etc.). A mobilidade depende da } \\
\text { estrutura física (vias, calçadas) mas também } \\
\text { da condição física e financeira das pessoas, } \\
\text { além do sistema de transporte disponível. } \\
\text { - Meio pela qual as pessoas e bens se locomo- } \\
\text { vem nas cidades. }\end{array}$ \\
\hline
\end{tabular}

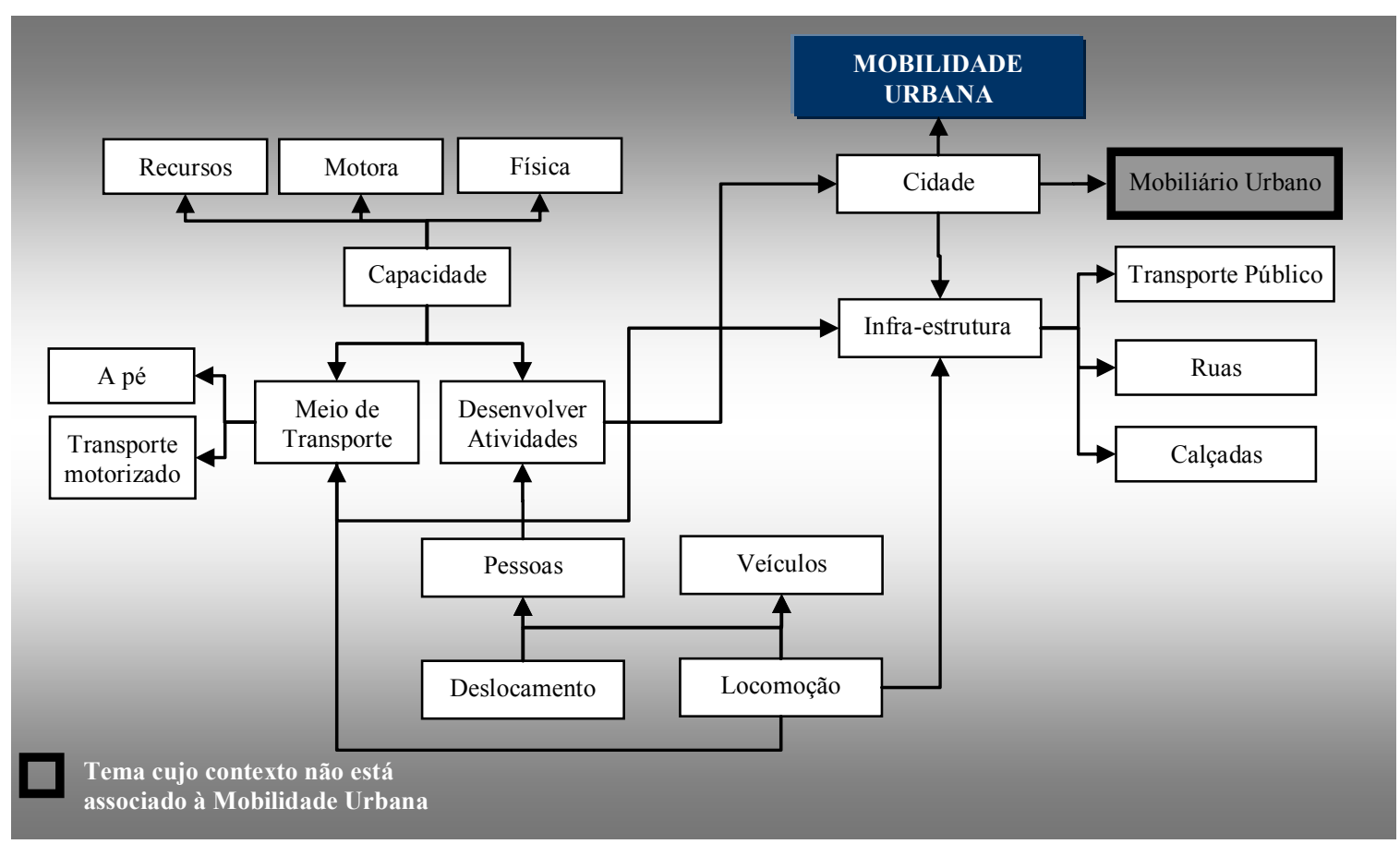

Figura 3: Mapa Cognitivo 1 - Visão geral de Mobilidade Urbana extraída do Questionário 1

Mapa 2 (Figura 6) pode-se observar uma ampliação no elenco de Temas. Muitas das palavras-chave identificadas nas respostas do questionário 2 representam os Temas considerados mais importantes na avaliação dos participantes no Módulo I do sistema PLANUTS (Crescimento Urbano, Sistema Viário, Acessibilidade Urbana, Impacto Ambiental, Mobilidade Urbana e Estratégias Econômicas) e considerados os mais urgentes para o município, identificados nas avaliações do Módulo III (Crescimento Urbano, População Urbana, Acessibilidade Urbana, Mobilidade Urbana e Impacto Ambiental).
De acordo com as respostas apresentadas nas Figuras 3 e 5 pode-se inferir que, tanto na definição de mobilidade quanto na determinação dos problemas associados à mobilidade, os técnicos municipais não incorporaram o conceito de sustentabilidade em suas definições. Aspectos ambientais, econômicos e sociais não foram mencionados pelos avaliadores. Neste sentido, pode-se afirmar que a visão deste grupo ainda estava associada ao antigo formato adotado no planejamento de transportes no Brasil. Em contrapartida, nos resultados apresentados nas Figuras 4 a 6 pode-se observar uma ampliação das palavras-chave associa- 


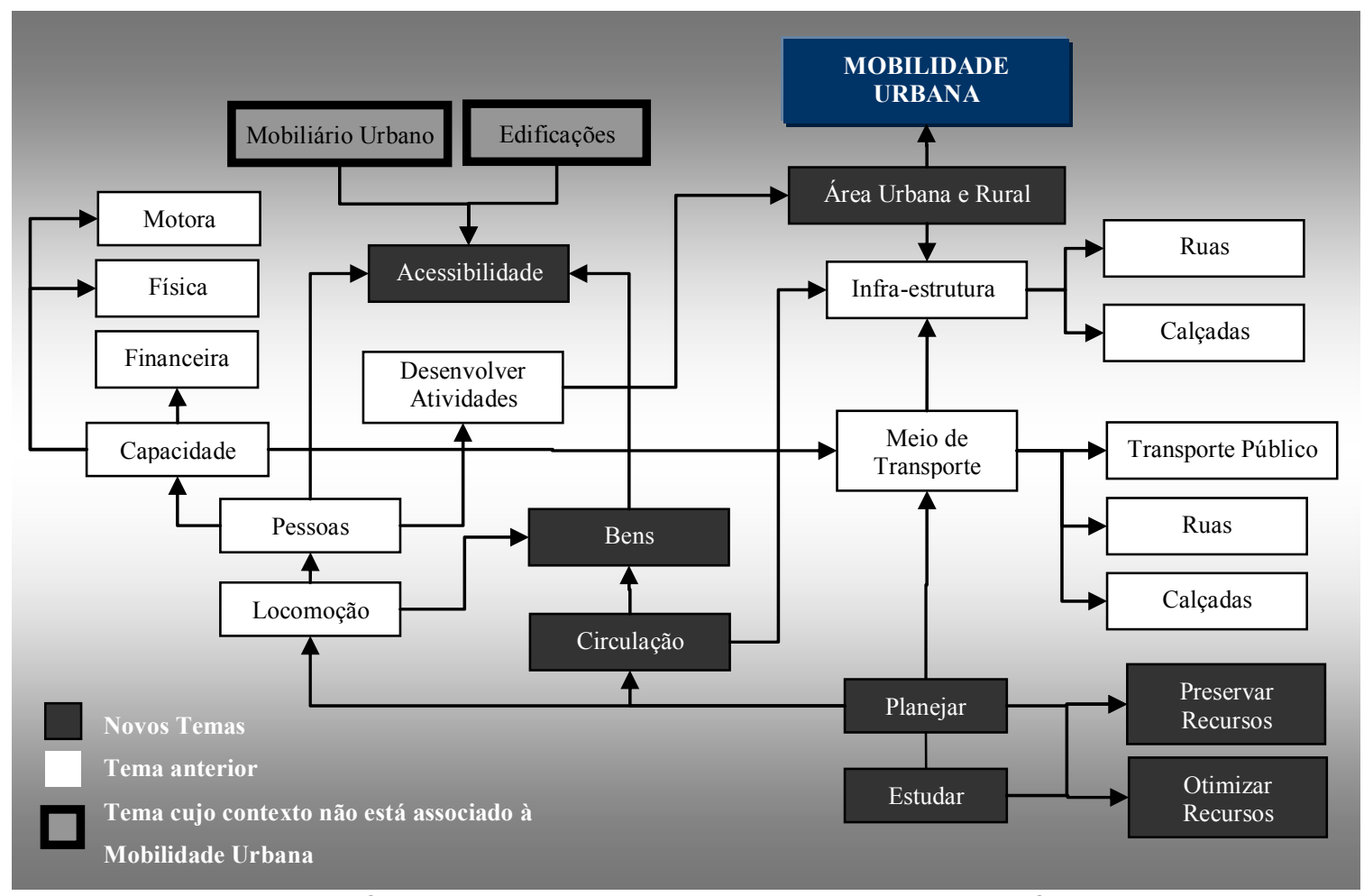

Figura 4: Mapa Cognitivo 2 - Visão geral de Mobilidade Urbana extraída do Questionário 2

Quadro 3: Transcrição das respostas dos especialistas para a questão que trata da identificação dos problemas de Mobilidade Urbana nos Questionários 1 e 2

\begin{tabular}{|c|c|c|}
\hline QUESTÃO & QUESTIONÁRIO 1A & QUESTIONÁRIO 2 \\
\hline $\begin{array}{l}\text { Quais os problemas da } \\
\text { cidade que não estão inseri- } \\
\text { dos neste Plano (mobilida- } \\
\text { de)? (Questionário 1) } \\
\text { ********* } \\
\text { Este Plano foi elaborado } \\
\text { para minimizar quais pro- } \\
\text { blemas da cidade? (Questi- } \\
\text { onário 1) } \\
\qquad X \\
\text { Cite alguns problemas } \\
\text { relacionados à Mobilidade } \\
\text { de sua cidade? (Questioná- } \\
\text { rio 2) } \\
\text { Objetivo - Identificar se } \\
\text { houve um avanço no grau } \\
\text { de conhecimento dos parti- } \\
\text { cipantes com relação a } \\
\text { questão da mobilidade e do } \\
\text { planejamento dos transpor- } \\
\text { tes. }\end{array}$ & 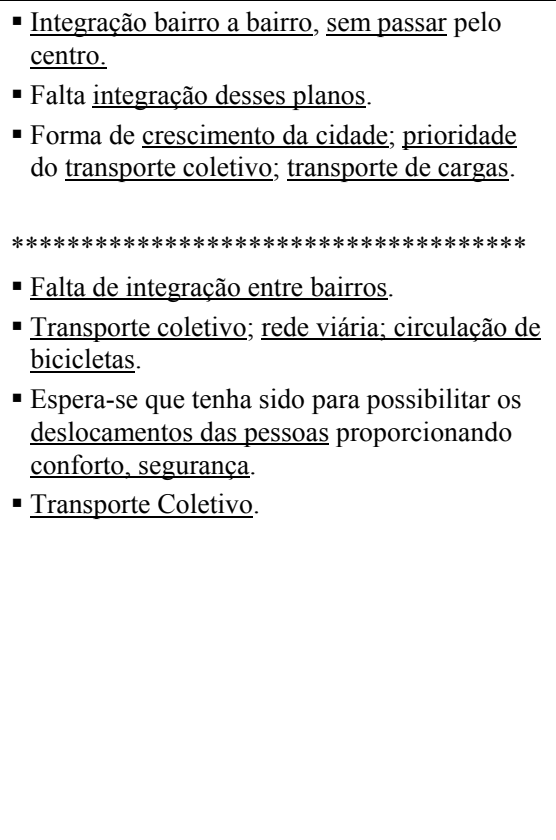 & $\begin{array}{l}\text { - Falta de transporte público. Falta de manuten- } \\
\text { ção das vias de rolamento. Áreas com vazios } \\
\text { urbanos. } \\
\text { - Falta de guias rebaixadas para cadeirantes. } \\
\text { Calçadas com degraus no sentido longitudi- } \\
\text { nal. Mobiliário urbano próximo ao muro das } \\
\text { casas. Falta de rampas em edifícios sem ele- } \\
\text { vadores. Falta de ciclovias. } \\
\text { - Barreiras físicas impostas pelos rios, ferrovias } \\
\text { e rodovias. Cidade muito dispersa, com mui- } \\
\text { tos vazios urbanos. Deficiência das estradas } \\
\text { rurais, nas calçadas e falta ciclovias. Sistema } \\
\text { de transporte coletivo com deficiências de } \\
\text { horário e rota. Renda de grande parte da po- } \\
\text { pulação. } \\
\text { - Falta de interligação entre bairros (várias } \\
\text { barreiras físicas), córregos, rodovias e ferro- } \\
\text { via. Bairros dispersos - cidade não compacta. } \\
\text { Falta de opções como ciclovia. Calçadas de } \\
\text { modo geral sem boa acessibilidade. Transpor- } \\
\text { te coletivo - alto custo. }\end{array}$ \\
\hline
\end{tabular}

das à mobilidade. Algumas destas palavras-chave podem ser encontradas inclusive em outros trabalhos, como o de Steg e Gifford (2005), pelo fato de que elas representam alguns dos problemas urbanos advindos da utilização dos meios de transporte motorizados individuais (utilização do automóvel) e que têm afetado de maneira negativa a qualidade de vida da população.

Esse mesmo padrão de variação foi observado na análise das demais questões, cujos detalhes podem ser encontrados em Magagnin (2008). A exemplo do que acontece nos casos aqui apresentados, todas as outras análises apontam para uma substancial diferença entre os conceitos de Mobilidade Urbana antes e depois da atividade com a ferramenta computacional. A explicação para essa diferença pode residir no fato de que o conceito inicial de Mobilidade Urbana dos técnicos não era amplo. Por este motivo o exercício de capacitação com a ferramenta computacional foi capaz de levar a tamanha ampliação da visão inicial. 


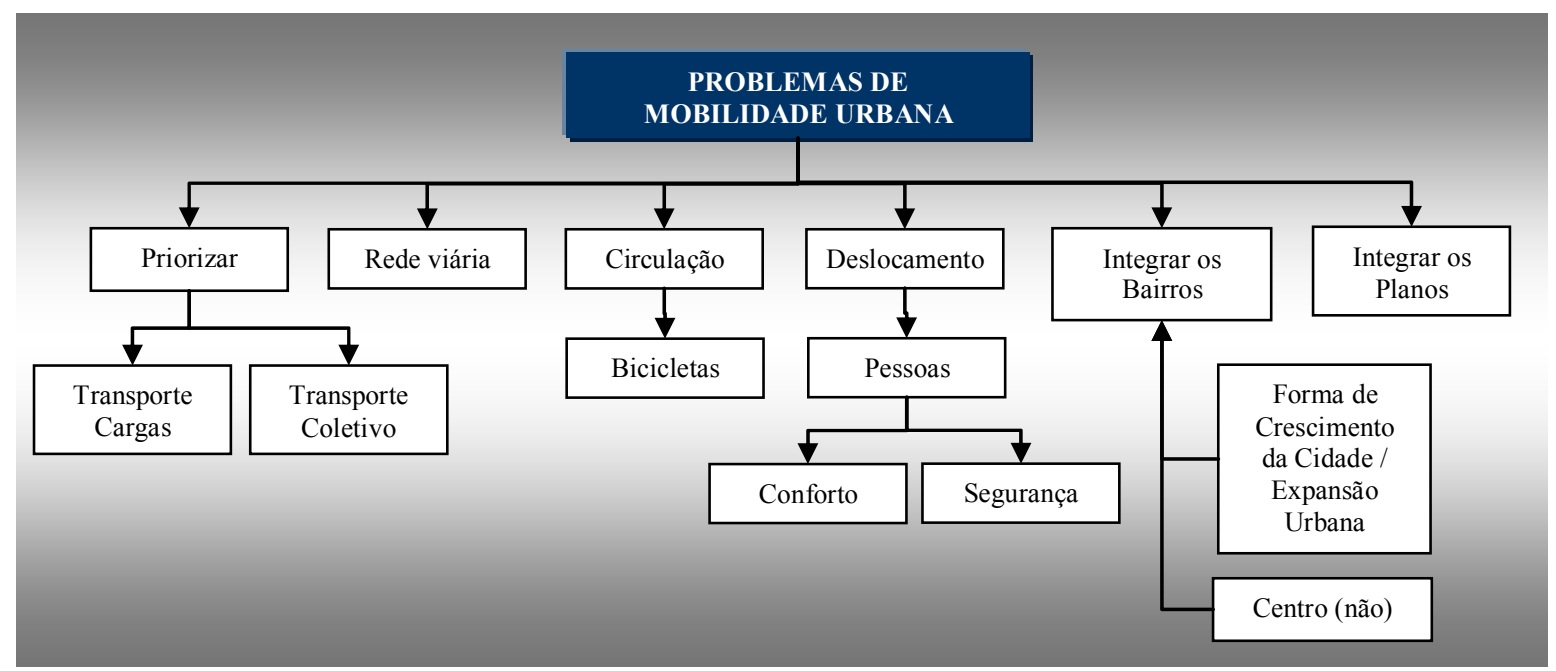

Figura 5: Mapa Cognitivo 1 - Identificação dos problemas de Mobilidade Urbana extraídos do Questionário 1

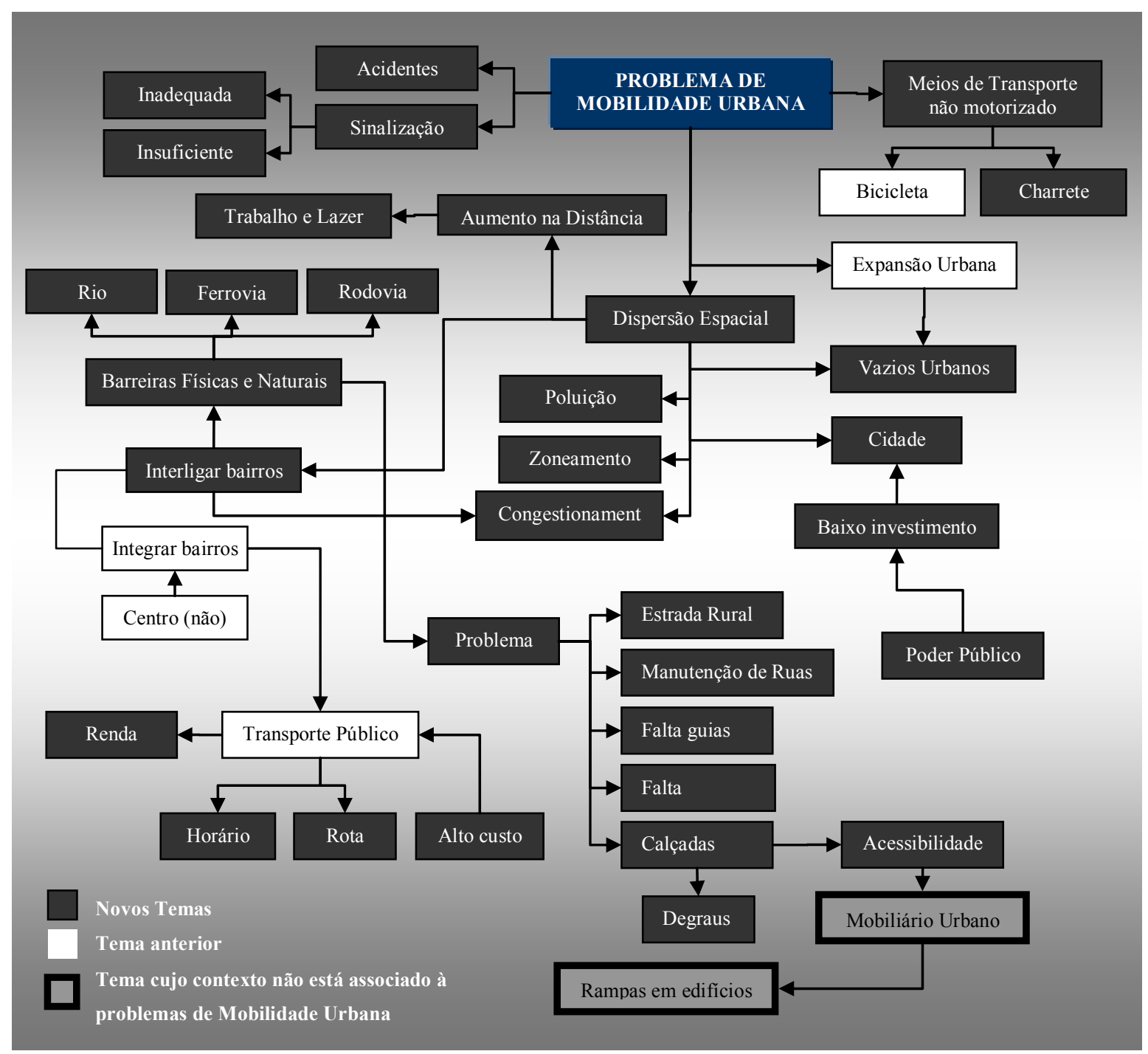

Figura 6: Mapa Cognitivo 2 - Identificação dos problemas de Mobilidade Urbana extraídos do Questionário 2

\section{CONSIDERAÇÕES FINAIS}

Diversas questões relacionadas ao conceito de mobilidade urbana começam a ser discutidas no Brasil, particularmente em alguns dos maiores centros urbanos e regiões metropolitanas. Os problemas urbanos que estão direta ou indiretamente relacionados a este conceito ainda não estão, no entanto, muito claros para uma parcela significativa da população. A proposta deste artigo era verificar a hipótese de que esta afirmação também se aplica aos especialistas, neste caso, técnicos ligados às áreas de planejamento urbano e de transportes. Isto foi possível através de uma análise de 
resultados obtidos em questionários aplicados antes e depois do uso de uma ferramenta computacional. A ferramenta, desenvolvida como parte de um Sistema de Apoio a Decisão para o planejamento da mobilidade urbana, foi concebida para a avaliação de indicadores de mobilidade. Além disso, no processo de atribuição de pesos e seleção de indicadores, os usuários são confrontados com inúmeros aspectos da mobilidade, o que pode levar naturalmente a uma mudança ou ampliação da visão que têm do conceito. Esse potencial foi testado através de técnicas de análise cognitiva aplicadas a dois questionários, como descrito na metodologia, permitindo confrontar a percepção dos usuários acerca do conceito de mobilidade urbana antes e depois do uso da ferramenta em um estudo de caso. Desta forma, foi possível avaliar a hipótese inicial de que a visão de mobilidade urbana dos técnicos pode ser também restrita.

De acordo com dados coletados antes do uso da ferramenta, através do Questionário 1, a mobilidade ainda era entendida essencialmente como sinônimo de planejamento de infra-estrutura (sistema viário), ou seja, ainda estava muito presente a definição do planejamento de transportes através de uma visão tradicional. A metodologia aplicada para a avaliação dos dois questionários permitiu constatar que pode haver a incorporação de uma nova visão na construção do conhecimento sobre a realidade da cidade, através da identificação e ordenamento dos problemas de mobilidade. Estes elementos foram identificados na comparação dos mapas cognitivos através de "novas palavras-chave", o que permitiu verificar uma mudança de paradigma (através da ampliação do conhecimento) sobre as questões que envolvem o planejamento da mobilidade no município.

Em síntese, pode-se afirmar que a metodologia adotada permitiu demonstrar que havia inicialmente uma visão parcial da mobilidade por parte dos técnicos. Mais ainda, a aplicação levou à conclusão de que parece ter havido uma significativa ampliação do grau de conhecimento dos participantes na definição dos temas que envolvem a Mobilidade Urbana ao usarem a ferramenta computacional. Isso torna a ferramenta particularmente útil para o planejamento da mobilidade, pois além de auxiliar diretamente no processo de planejamento, leva ao mesmo tempo a uma ampliação da visão que os técnicos possuem do foco da sua atividade, a mobilidade urbana.

\section{AGRADECIMENTOS}

Os autores agradecem ao CNPq, à CAPES e à FAPESP por contribuírem para diferentes fases do desenvolvimento da pesquisa que deu origem a esse artigo.

\section{REFERÊNCIAS BIBLIOGRÁFICAS}

Bardin, L. (1977) Análise de Conteúdo. Edições 70. Lisboa.

Black, J.A., Paez, A. e Suthanaya, P.A. (2002) Sustainable urban transportation: performance indicators and some analytical approaches. Journal of Urban Planning and Development, vol. 128, p. 184209.

Gudmundsson, H (2001) Indicators and performance measures for Transportation, Environment and Sustainability in North America. Report from a German Marshall Fund Fellowship 2000. Individual study tour October 2000. Research Notes No. 148. Disponível em:

http://www2.dmu.dk/1_viden/2_Publikationer/3_arbrapporter/rap porter/AR148.pdf

Gudmundsson, H (2004) Sustainable transport and performance indicators. Em R.E. Hester and R.M. Harrison (ed.) Transport and Environment, Issues in Environmental Science and Technology. The Royal Society of Chemistry, p. 35-64, Cambridge, U.K.

Litman, T (2006) Evaluating Transportation Land Use Impacts. Victoria Transport Policy Institute. GTZ Transport and Mobility Group. Disponível em: http://www.vtpi.org

Loukopoulos, P. e Scholz, R.W. (2004) Sustainable future urban mobility: using area development negotiations for scenario assessment and participatory strategic planning. Environment and Planning A, vol. 36, p. 2203-2226.

Nicolas, J.-P.; Pochet, P. e Poimboeuf H. (2003) Towards sustainable mobility indicators: application to the Lyons conurbation. Transport Policy 10, p. 197-208.

Magagnin (2008) Um Sistema de Suporte à Decisão na internet para o planejamento da Mobilidade Urbana. Tese (Doutorado). Escola de Engenharia de São Carlos, Universidade de São Paulo, São Carlos.

Ministério das Cidades (2006). Curso Gestão Integrada da Mobilidade Urbana. Módulo I: Política Nacional de Mobilidade Urbana. Ministério das Cidades, Programa Nacional de Capacitação das Cidades, Brasília, Março, 2006. Disponível em: http://www.cidades.gov.br/CursoSemob/modulos.html

Ministério das Cidades e IBAM (2004) Mobilidade e Politica urbana: Subsídios para uma Gestão Integrada. Disponível em: http://www.cidades.gov.br/media/MobilidadeePoliticaUrbana.pdf

Pereira, J.C.R. (2001) Análise de dados qualitativos: estratégias metodológicas para as ciências da saúde, humanas e sociais ( $\left.3^{\mathrm{a}} \mathrm{ed}\right)$. EDUSP. São Paulo.

Pidd, M. (2003) Tools for Thinking. Modelling in Management Science. John Wiley \& Sons. ( $\left.2^{\text {nd }} e d\right)$, England, UK.

Richardson, B.C. (2005) Sustainable transport: analysis frameworks. Journal of Transport Geography, vol. 13, p. 29-39.

Sant'Anna, R.M. de (2007) O ambiente viário na percepção de pedestres idosos: uma contribuição da psicologia social. Anais do XXI Congresso de Pesquisa e Ensino em Transportes. Rio de Janeiro - RJ. Anais em CD.

Silva, A.N.R.; Costa, M.S.; Macedo, M.H. (2007) Multiple Views of Sustainable Urban Mobility in a Developing Country - The Case of Brazil. Proceedings of 11th World Conference on Transport Research, WCTR, Berkeley. Anais em CD.

Steg, L. e Gifford, R. (2005) Sustainable transportation and quality of life. Journal of Transport Geography, vol. 13, p. 59-69.

UITP (2004) Ticket to the Future 3 stops to Sustainable Mobility. Disponível em: http://www.uitp.org/Project/pics/susdev/Brochure-EN.pdf 